\title{
Im Spital
}

\section{Daniel Oertle}

Dr. med., Hausarzt in Zürich

Er hat ein böses Knie und ist für die Operation im Neuen Spital angemeldet. Schon das Einchecken im Neuen Spital ist bemerkenswert. Da steht ein junger flotter Mann in Anzug und Krawatte wie der Concierge in einem mindestens Fünfsternehotel hinter einem grossen breiten Desk (Nussbaum, massiv) und fragt laut und höflich nach Namen, Geburtstag und Befinden. Für die Krücken sind im Desk Vertiefungen eingelassen, um sie einzuhängen, sehr elegant. Also ganz einfach, zuerst an den Schalter 3 den Gang hier rechts, dann zum Röntgen den Gang da zweimal links dann rechts, dann in die Präoperative, OK?

Er erinnert sich an den schrulligen Portier im kleinen Spital, er wurde später sein Patient, und da sagten sie sich Du, der Franz also, der stand tagein, tagaus in seiner Loge, trug einen blauen Arbeitsmantel und überblickte den Eingang. Franz war, das sagte er jedem, schon seit soundsovielen Jahren Portier, solange es eben dieses Spital gäbe, er kannte alle. An Franz kam keiner vorbei. Er sah sofort, ob ein Notfall ein Notfall war, und avisierte die Anästhesie. Einfache Schnittwunden links, Verdacht auf Infarkt rechts. Franz war immer zur Stelle. Ferien

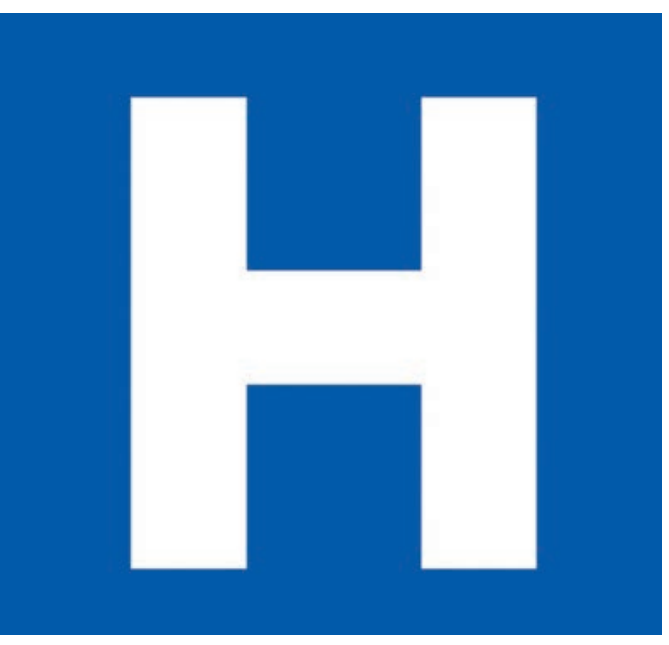

M. das Lied singen "vo däm wo vom Amt isch ufbotte gsy, am Fritig vor de Nüne» - da kontrolliert er ängstlich seine Armbanduhr. Eine freundliche junge Frau mit einem ganz langen Namen, dahinter steht «in Ausbildung», bringt ihn schliesslich zum Schalter 3. Die Schalterfrau: Wo er denn bitte sehr so lange gewesen sei? Nun, äxgüsi, die Baustelle, das Knie - die freundliche junge Frau mit dem langen Namen ist leider schon hinter der nächsten Abzweigung verschwunden.

Die Röntgerei geht super effizient, die Röntgenassistentin ist sehr nett, alles sei tipptopp, sagt sie zweimal, alles tipptopp - meint sie das Knie, aber das tut doch so weh?

Dann die Präoperativen, drei verschiedene, immer sieben Seiten Papier, hier bitte unterschreiben. Er schaut wolle er dann machen, wenn er pensioniert sei, also nie. Er blieb ganz lange Portier und wetterte noch eine Woche vor seinem Tod, dass die Italiener sein Südtirol gestohlen hätten. Aus diesem Südtirol kam er als Melker in die Schweiz, führte später ein Milchlädeli und wurde dann Portier. Der beste Portier. Er wusste alles, handelte schnell und präzise, war manchmal übellaunig, manchmal freundlich und bewachte des Autors Velo, das er verbotenerweise neben dem Eingang parkieren durfte. Aber das ist eine andere Geschichte. Jetzt ist der Portier ein freundlicher junger Concierge mit Krawatte. Zuerst links, dann zweimal rechts, dort ist ein rot-weisses Absperrband: Baustelle. Also zurück, zweimal links und einmal rechts, oder, wie bitte ... der Gang wird immer länger. Er muss sich auf ein schmales Sims setzen, eben: das Knie. Von weit her hört er Mani bei «Ja» setzt. Dann der Anästhesist, auch sehr freundlich, auch sehr kompetent, eher nicht mit dem Velo zur Arbeit. Das die Risiken, hier bitte unterschreiben. Er stellt sich jetzt ein krummes kleines Fraueli aus Ostanatolien vor, ich nix vil Deutsch sprech. Sie sässe mit ihrem Neffen da, der versuchte, das zu übersetzen, was er auch nicht versteht, und der auch für seine Tante unterschriebe, weil sie das nie gelernt hatte. Er ist froh um seine Deutschkenntnisse und unterschreibt schnell. Dann kommt die freundliche Pflegefachfrau, stellt die gleichen Fragen, er sagt ja oder nein und erschrickt plötzlich, als sie etwas fragt, was beide Ärzte nicht gefragt hatten. Ob er so kurzfristig seine Praxis organisieren könne, wer denn jetzt seinen Patienten schaue? Er hat plötzlich wässrige Augen: Da wurde etwas Persönliches gefragt. Bitte hier unterschreiben. 
Er tritt ins Spital ein und wird sehr freundlich vom jungen Mann mit der Krawatte empfangen. Der Anästhesist kommt aus dem Iran und sticht sehr feinfühlig. Die Lagerung übernimmt ein Kurde mit einem freundlichen verwitterten Gesicht, der von seinen Bienen erzählt. Die Leitungen legt eine freundliche Frau aus Finnland, perfekt. Die Operation geht schnell, wie geplant, er ist ein paar Tage auf Abteilung. Auch hier sind alle äusserst freundlich, er wird perfekt gepflegt. Nur kann er sich keine Namen merken, am Morgen kommt Pflegfachfrau X, dann kommt jemand, der die Vitalparameter kontrolliert, dann jemand mit einem $\mathrm{Ta}$ blett voller Pillen, dann die Fachfrau Verpflegung, dann jemand, der sauber macht und freundlich guten Tag sagt, dann die Physiotherapeutin, die sein Bein auf einen Kniebeugeautomaten legt, dann wieder Frau X, die sich in den Urlaub verabschiedet, dann kommt die Fachfrau Schmerz, dann eine nette Frau, die Haut und Einstichstellen der Katheter kontrolliert, sehr kompetent. Alle haben auf ihrem Wägelchen einen geöffneten Laptop dabei, in den sie emsig schreiben. Auf dem Bildschirm muss sich Interessantes abspielen, denn alle blicken unablässig auf den Screen. So lernt er in wenigen Tagen zwanzig, vielleicht fünfundzwanzig sehr freundliche, sehr nette kompetente junge Leute kennen: Er fühlt sich geschmeichelt, dass sich so viele junge Leute um ihn kümmern.

Die Visite: guten Tag, Knie links, System XY, Zement, problemlos. Auf Wiedersehen.

Er hätte gerne etwas von seiner Übelkeit gesagt, aber da war die Visite schon weg. Sein verehrter Lehrer Renato hatte ihnen beigebracht, dass zum Beispiel Digoxin-Überdosierungen ( $\mathrm{ja}$, damals behandelte man noch mit Digoxin) nur in Dementen-Abteilungen von Pflegeheimen vorkämen. Alle anderen Patienten merkten genug früh, wenn ihnen die kleinen weissen Pillen nicht gut täten, und würden sie aussortieren. Also erinnert er sich an Renato und sortiert zuerst die runden blauen und dann die länglichen weissen und dann auch die groben weissen Pillen aus. Im obersten Nachttischschublädli ist ein Fach, da passen die Pillen perfekt hinein, und das Fach wird noch fast voll. Jetzt geht es seinem Magen langsam besser.

Einschub: Sein Vater und dessen Schwester Anna kamen aus den Bergen. Das Geld reichte nur für die Ausbildung seines Vaters, also wurde Anna Krankenschwester, das kostete nichts. Tante Anna war fromm, hatte grosse Hände und ein liebes Gesicht und trug die silberne Brosche ihres Ordens. Sie erzählte ihm einmal, ihr Arbeitstag hätte morgens um fünf begonnen. Sie hätten in den Patientenzimmern die Öfen eingefeuert und die Böden geschrubbt, dann die Patienten gewaschen, gepulst, gemetert (Sie erinnern sich an die Farbstifte, rot an der einen, blau an der andern Spitze?), dann das Frühstück verteilt, die Patienten für die Visite parat gemacht und so weiter und so weiter. So wären sie immer bei den Patienten gewesen, hätten gesehen, dass Frau Meier nichts essen wollte, Frau Weber einen Dekubitus und Frau Müller einen grossen Kummer hatte. Abends seien sie ziemlich müde gewesen, das schon. Und dann kam noch ein Seufzer: «Es sei streng, aber halt schön xi damals.» Er hatte vergessen, Tante Anna zu fragen, was sie verdient hätten, jetzt kann er sie nicht mehr fragen. Aber er wäre gerne ihr Patient gewesen.

(Wenn Sie dem Autor dieser Zeilen jetzt einen Leserbrief schreiben wollen: Tun Sie es nicht. Natürlich haben Sie recht, die Krankenschwestern wurden damals schlimm ausgebeutet, heute haben sie ein stolzes Berufsbild, können doktorieren, Professorinnen werden. Alles wurde besser. Schreiben Sie nicht, der Autor weiss es, er ist ein alter Nostalgiker, hoffnungslos.)

Er ist froh, als er das schöne freundliche Spital verlassen kann. Alles ist gut gegangen. Er ist dem Spital, dem Chirurgen und all den freundlichen Pflegenden sehr dankbar für ihre Arbeit. Aber, er wagt es kaum zu sagen, er hatte Heimweh. Er muss an die kleine Frau aus Ostanatolien denken, die vielleicht ein ossär metastasierendes Mammacarcinom hat und drum so krumm ist. Was die wohl für Heimweh hat? Gibt es in unseren Neuen Spitälern eine Fachfrau Heimweh?

Er weiss jetzt: Das grosse weisse «H» auf blauem Grund vor den Spitälern steht für Heimweh.

Bildnachweis

๔ Alexander Kharchenko | Dreamstime.com

\section{Ärzte und Ärztinnen als Patienten}

Haben Sie sich als Ärztin oder Arzt auch schon unversehens in der Patientenrolle wiedergefunden? Wie haben Sie diesen Perspektivenwechsel erlebt? Wenn Ihre Erfahrungen für die Leserschaft der SÄZ interessant sein könnten, möchten wir Sie dazu animieren, uns dazu einen Artikel von maximal 8000 Zeichen Umfang an redaktion.saez[at]emh.ch einzureichen. Ihr Manuskript wird dann von der Redaktion geprüft und bei positiver Beurteilung im Rahmen der Serie «Ärztinnen und Ärzte als Patienten" publiziert. 